\title{
Perfis das Notícias sobre o Câncer no Correio da Manhã e no The New York Times nos Anos 1931-1932 e 1948-1949 Profiles of Cancer News in Correio da Manhã and The New York Times Newspapers during the Years 1931-1932 and 1948-1949 Perfiles de las Noticias sobre Cáncer en el Correio da Manhã y The New York Times en los Años 1931-1932 y 1948-1949
}

Claudia Jurberg' ${ }^{\text {; }}$ Marina Verjovsky²; Gabriel Pereira ${ }^{3}$; Luiz Antonio Teixeira ${ }^{4}$

\begin{abstract}
Resumo
Introduçáo: No início do século passado, o câncer já se caracterizava como uma das doenças crônico-degenerativas mais letais e começou a demandar mais atençáo dos governos. Portanto, alguns países empreenderam novas medidas políticas, como o aumento de investimentos científicos em busca de uma cura. Objetivo: Este artigo procura evidenciar as características dos conteúdos das matérias jornalísticas sobre o câncer nos jornais brasileiro e norte-americano Correio da Manhã e The New York Times, nas décadas de 1930 e 1940, através da análise das notícias publicadas em quatro anos selecionados (1931, 1932, 1948 e 1949). Método: Foram realizadas pesquisas no acervo documental da Biblioteca Nacional e no acervo digital do The New York Times. Em paralelo, também foi realizada uma análise do que foi publicado sobre o tema câncer nos periódicos científicos, acessível através do portal do PubMed, durante a mesma época. Resultados: Enquanto, no Correio da Manhã, foram identificadas 56 reportagens sobre o tema no período estudado, no jornal americano, foram identificadas 540 notícias, ou seja, quantidade praticamente dez vezes superior. Conclusáo: Os achados demonstram uma imprensa brasileira tímida e, por vezes ingênua, diante de promessas de curas milagrosas, como pomadas contra o câncer de pele. Enquanto isso, a mídia norte-americana priorizava abordagens sobre investimentos para a pesquisa da doença, destacava as conferências de cientistas especialistas no assunto e até o uso de experimentação animal na pesquisa do câncer; embora, em certas ocasiôes, também tenha apostado em inovaçôes científicas que a história mostrou como iniciativas infrutíferas.
\end{abstract}

Palavras-chave: Neoplasias/história; Jornais/história; Jornalismo/história; Brasil; Estados Unidos; Artigo Histórico

\footnotetext{
${ }^{1}$ Jornalista do Instituto Oswaldo Cruz/Fiocruz e do Instituto de Bioquímica Médica/UFRJ. Doutora em Educação, Gestão e Difusão em Biociências pela Universidade Federal do Rio de Janeiro (UFRJ).

${ }^{2}$ Jornalista. Doutoranda do Programa de Pós-Graduação em Educação, Gestão e Difusão em Biociências do Instituto de Bioquímica Médica da UFRJ.

${ }^{3}$ Graduando da Escola de Comunicação da UFRJ.

${ }^{4}$ Historiador da Casa de Oswaldo Cruz/Fiocruz. Doutor em História Social pela Universidade de São Paulo (USP).

Endereço para correspondência: Programa de Oncobiologia/Instituto de Bioquímica Médica. Av. Carlos Chagas Filho, 373 - bloco H - sala H2003. Cidade Universitária. Rio de Janeiro (RJ), Brasil. CEP: 21941-902. E-mail. cjurberg@bioqmed.ufrj.br.
} 


\section{INTRODUÇÃO}

$\mathrm{Na}$ década de 1930, a sociedade brasileira sofreu alteraçóes significativas decorrentes do processo de urbanização e industrialização, intensificados no final da década anterior. Nesse contexto, o aprofundamento da crise econômica mundial, a partir de 1929, e o contínuo desgaste do modelo político baseado na rotatividade das oligarquias agrárias paulistas e mineiras no poder federal determinaram o fim da chamada Primeira República.

A ascensão de Getúlio Vargas ao governo do país, através de um golpe de Estado, trouxe à tona uma nova concepção de Estado, em muitos momentos autoritária, em que novas demandas sociais, principalmente as provenientes das camadas médias urbanas, passaram a fazer parte da agenda do governo. Seu longo período ininterrupto de governo (1930-1945) foi marcado pela tentativa de consolidação de um projeto de integração nacional, valorização do trabalho e do operariado urbano e de industrialização do país.

Em relação à saúde, as açôes governamentais, até então direcionadas ao estabelecimento de um aparato de saúde de âmbito nacional, iniciadas a partir da década de 1920 com a Criação do Departamento Nacional de Saúde Pública, passaram a dividir espaço com as medidas de reformulação e ampliação do sistema de assistência médica do tipo seguro saúde, direcionadas ao operariado urbano, que funcionava através dos Institutos de Aposentadorias e Pensôes ${ }^{1}$.

No campo mais específico da saúde pública, o início do período Vargas se caracterizou por um total imobilismo, decorrente das dificuldades econômicas e das lutas políticas entre as antigas oligarquias e os novos ocupantes dos postos de poder. Essas dificuldades fizeram com que o Ministério da Educação e Saúde, criado em 1930, permanecesse vários anos com uma atuação de menor envergadura do que a da instituição que o precedeu. Somente a partir de 1937, no período de endurecimento do regime que ficou conhecido como ditadura do Estado Novo, uma reforma ministerial deu nova dinâmica ao Ministério, ampliando seu nível de atuação a partir da maior centralizaçáo e normatização das açóes relacionadas à saúde no Brasil. A partir de então, novas atividades seriam colocadas em prática, sendo de especial importância os Serviços Nacionais, um conjunto de serviços direcionados ao controle das doenças entáo vistas como entraves ao desenvolvimento do país ${ }^{2}$.

No que tange aos principais agravos à saúde que afetavam a população, as doenças infecciosas ainda se mostravam como problemas centrais nesse período. Para controlá-las, foram reforçadas as campanhas de profilaxia e, a partir de 1938, criados Serviços Nacionais específicos a elas direcionadas. Na época, "a febre amarela ainda ameaçava a capital e os portos litorâneos, a malária grassava pelo interior do país, a hanseníase e as doenças venéreas tinham altos índices de incidência e a tuberculose continuava sendo o mais grave problema sanitário das cidades"3. Essas doenças eram responsáveis por $46 \%$ de todos os óbitos. Por outro lado, as doenças do aparelho circulatório representavam apenas $12 \%$, nessa mesma década ${ }^{4}$. Infelizmente, pouco se sabia sobre a ocorrência do câncer entre a população brasileira:

Qual a frequência do câncer entre nós? Onde estão os dados de uma estatística aproximada, que nos habilitem a ajuizar da difusão do mal e apreciar suas consequências sociais? Sabemos apenas, e tanto basta para avivar a nossa previdência, que as afecçóes cancerosas fazem elevado número de vítimas em toda vasta extensão do nosso território 5 .

Apesar da falta de estatísticas, o câncer nesse período começava a ser visto como um problema que necessitava de atenção da saúde pública, pois já se caracterizava como uma das doenças crônico-degenerativas mais letais. A partir da ampliaçáo do interesse médico pela doença, foi instalado na capital federal um Centro de Cancerologia, em 1937, que passou a ser dirigido por Mário Kroeff, um dos pioneiros do estudo do câncer no país. Quatro anos depois, foi criado o Serviço Nacional do Câncer (SNC), que também era dirigido por Kroeff e tinha como objetivo coordenar a política de controle da doença no país. Apesar das dificuldades orçamentárias iniciais, o SNC se mostrou fortemente atuante em políticas de conscientizaçáo da população em relação à doença e na divulgação das formas de prevenção e diagnóstico precoce. No âmbito do Distrito Federal, o Centro de Cancerologia foi aos poucos se institucionalizando. Em 1944, passou a se denominar Instituto de Câncer, funcionando, a partir do ano seguinte, nas dependências do Hospital Gafree Guinle, onde ampliou seu conjunto de atividades clínicas e se consolidou como centro de referência em relação à doenças ${ }^{5}$.

Durante a "Era Vargas", a imprensa do Rio de Janeiro presenciou mudanças significativas decorrentes da relação desta com o poder e o papel dos jornalistas naquele momento ou apoiando de forma irrestrita o governo ou, por outro lado, referendando suas açōes ${ }^{6}$. O foco da imprensa nos anos 1930 são, portanto, os fatos de evidência política, sendo que a maioria dos veículos considerava conveniente amparar açôes governamentais a sofrer possíveis sançôes. Como Vargas ainda não havia instituído nenhum órgáo de controle da imprensa - o Departamento de Imprensa e Propaganda (DIP) só seria criado em 1937 -, as reportagens eram produzidas com maior liberdade e sempre alinhadas com a posição política do jornal.

Mas, conforme salienta Barbosa ${ }^{6}$, em meados dessa década, a política ganhou cada vez mais destaque em 
detrimento de outros assuntos de interesse dos leitores que praticamente estavam ausentes das publicaçóes da época. Essa ampliação do espaço destinado à área está intimamente relacionada à ação do DIP, cuja missão era divulgar a ideologia varguista.

Se havia uma grande variedade de jornais, com preferências políticas declaradas, seus estilos pareciam encontrar muita coisa em comum. A imprensa da época procurava equilibrar as notícias vindas do exterior com os fatos noticiosos no Brasil. Havia um grande interesse em conhecer o que se passava no exterior, mas os acontecimentos políticos nacionais ganhavam em destaque e costumavam ocupar a maior parte das manchetes de primeira página. As pequenas notícias cotidianas conquistaram espaço com o tempo. Manifestaçóes políticas nos periódicos ficam ainda mais claras na década de 1940, mostrando como a imprensa soube explorar sua liberdade após o fim do DIP, e voltou a ser um instrumento político importante ${ }^{7}$.

Já no fim da década de 1940, nos anos 48 e 49, a situação política se tornou bastante diferente com o retorno à democracia. Vargas não era mais o presidente, sendo esse posto assumido por Eurico Gaspar Dutra. Nessa fase, o brasileiro ainda sentia os ecos da Segunda Guerra Mundial e estava com interesse redobrado nas notícias do exterior ${ }^{8}$. O interesse pelas notícias contribuía para a perenidade dos jornais. Assim, os mesmos jornais da década de 1930 ainda se mantinham em atividade, e outros apresentavam um crescimento significativo em importância, como O Globo, que se tornaria no futuro o maior jornal do Estado do Rio de Janeiro ${ }^{8}$.

Na década de 1940, existiam no Distrito Federal cerca de 20 jornais. Nessa época, ainda eram comuns os jornais matutinos e vespertinos, sendo esses os mais populares. Entre os periódicos de maior destaque, estavam o centenário Jornal do Commercio, o Jornal do Brasil, Diário de Notícias, A Manhã e Correio da Manhã 9 .

Vale esclarecer que, até o fim da década de 1940 e início dos anos 1950, não havia curso superior em jornalismo no Brasil, o que cooperava para uma prática mais próxima da literatura. Porém, com o surgimento dos cursos de nível superior, o jornalismo aos poucos conquistou um espaço autônomo, dando início ao seu processo de profissionalização. Até então, essa prática era apenas uma ocupação provisória e muito atrelada aos literatos, à elite ${ }^{10}$ e aos políticos ${ }^{11}$. Todavia, nesse momento, a maioria das redaçóes ainda era composta por profissionais sem ensino superior e por uma parcela menor (a elite) formada principalmente nas Faculdades de Direito ${ }^{12}$.

Se por um lado, a saúde pública conquistou destaque como ação de governo nas décadas de 1930 e 1940 e, por outro, a imprensa oscilava entre liberdade e a censura imposta pelo DIP, quais seriam as características da divulgação da temática câncer nos jornais Correio da Manhã e; por outro lado, como um jornal internacional de grande abrangência como o The New York Times (NYT) abordava o mesmo tema.

É nesse cenário que se procurou neste artigo analisar a cobertura do tema câncer, os anos 1931 e 1932 e 1948 e 1949, por um dos principais jornais brasileiros dessa época, o Correio da Manhá. Esse período foi selecionado por estar localizado alguns anos antes e outros após a criação, em 13 de janeiro de 1937, do Centro de Cancerologia, mais tarde Instituto Nacional de Câncer José Alencar Gomes da Silva (INCA). Em relação à escolha do Correio da Manhã, esta se explica por ter empreendido a mais ampla cobertura mediática da época sobre a temática câncer.

Levando em consideração os esforços pela melhoria das condiçôes na área da saúde e as implementaçôes técnicas e projetos oficiais do governo Vargas, sobressai a questão de como essas campanhas eram recebidas pela população em geral e, quanto, na realidade, de informação foi transmitida à sociedade. Qual era o tipo de informação em câncer circulante na época? Que tipo de abordagem o Correio da Manhã dedicava à temática? E o que a imprensa norte-americana, mais especificamente, a do periódico NYT, divulgava sobre o tema no mesmo período? Dirigir o olhar para um dos mais importantes ou, como identificado por Negreiros ${ }^{13}$, como o maior jornal do Rio de Janeiro, enquanto existiu; e comparar o tema câncer em um dos veículos de maior tradição nos Estados Unidos podem tornar-se, portanto, atividades altamente reveladoras e enriquecedoras.

A escolha de um jornal americano como o NYT, que foi fundado em 1851 e é considerado o maior jornal metropolitano americano, sendo sua força creditada à excelência editorial, se reflete numa das tradiçóes daqueles tempos quando os médicos brasileiros partiam para os Estados Unidos em busca de maior especialização. Nesse sentido, nossos interesses se voltam para descobrir o que a imprensa norte-americana publicava sobre a temática nesse período.

Ao se analisar a quantidade de ocorrências de citaçóes sobre o câncer, as formas de abordagem e o conteúdo das matérias do Correio da Manhã em quatro anos selecionados dentro do período proposto, procurou-se averiguar as principais situaçôes encontradas e comparar alguns aspectos dessas notícias com as reportagens veiculadas pelo NYT. Desse modo, buscou-se ter uma visão diferenciada sobre a oferta e disponibilidade de notícias sobre a doença. Procurou-se observar como encontrava-se a divulgação científica e de saúde na época e, em que medida, poderia ser comparada à divulgação da temática nos Estados Unidos. Além disso, comparar com um panorama da pesquisa científica na área.

Portanto, este artigo tem como objetivo evidenciar as características dos conteúdos das matérias jornalísticas 
sobre o câncer nos jornais brasileiro e norte-americano Correio da Manhã e NYT, nas décadas de 1930 e 1940, através da análise das notícias publicadas em quatro anos selecionados (1931, 1932, 1948 e 1949).

\section{MÉTODO}

Este estudo baseou-se inicialmente na publicação Resenha da Luta Contra o Câncer no Brasil ${ }^{14}$ que traz uma coletânea de notícias publicadas na imprensa sobre a doença nas décadas de 1920, 1930 e parte dos anos de 1940 como documentário das primeiras açóes desenvolvidas pelo Governo para o controle da doença. Como entre as notícias publicadas neste livro, a maioria foi veiculada no Correio da Manhá, optou-se por analisar em maior profundidade este veículo da mídia. O Correio da Manhã, criado em 1901, era o maior jornal da então capital federal, e manifestava clara simpatia pelo presidente Vargas. Outros jornais importantes do período, que também apresentavam as mesmas preferências políticas, eram o Diário Carioca e o Jornal do Commercio - até hoje o mais antigo veículo em circulaçáo ininterrupta na América Latina ${ }^{15}$. Na oposição, um dos mais expressivos jornais da época era A Noite.

Após a escolha do jornal Correio da Manhã, buscou-se a fonte de coleta de dados no acervo original de exemplares preservados em formato de microfilmes da seção de periódicos da Biblioteca Nacional, no Rio de Janeiro, uma vez que o Correio da Manhã foi extinto. Foram selecionados os anos de 1931, 1932, 1948 e 1949 para estudo de caso, pois pretendia-se investigar um período antes da criação, em 13 de janeiro de 1937, do entáo Centro de Cancerologia, embriáo formador do atual INCA, e compará-lo com um período após essa ocorrência. Além desse aspecto, a escolha do início dos anos 1930 como período de pesquisa se deveu ao fato de que o final da década anterior assistiu à primeira mobilização médica em relação ao câncer. Em 1929, as principais agremiaçôes médicas do Estado - a Academia Brasileira de Medicina e a Sociedade de Medicina e Cirurgia do Rio de Janeiro - se uniram na elaboraçáo de um evento denominado semana do Câncer que objetivou chamar a atenção dos médicos e do público leigo para a doença através de conferências públicas e discussóes dirigidas à classe médica. Nesse sentido, nossa pesquisa poderia identificar as repercussóes desses eventos no interesse pela doença.

Sob cada exemplar do Correio da Manhã, nesses respectivos anos, foi realizada uma "garimpagem", na qual se procurou examinar atentamente as notícias em busca da temática câncer, na divulgação de novos casos, descobertas relativas a novas modalidades terapêuticas da doença e esforços na busca do entendimento de suas origens e em métodos de cura.
$\mathrm{O}$ acervo da biblioteca foi minuciosamente pesquisado. A cada descoberta de uma notícia, foi solicitada uma cópia do microfilme em unidades de CD. As mesmas foram impressas para análise.

Em paralelo, buscaram-se as características da divulgação do câncer, no conteúdo disponibilizado de forma virtual pelo jornal NYT. Ininterrupto desde sua criação, foi fundado 50 anos antes do Correio da Manhá, até hoje circula e ainda possui arquivo digital para pesquisa. Originalmente, o jornal circulava todos os dias, excluindo o domingo, o que mudou durante a Guerra Civil Americana (1861-1865). O NYT iniciou a edição on-line em 1996 e, desde entáo, é uma referência, pois permite o acesso livre, porém reduzido, ao seu conteúdo, inclusive histórico.

A escolha do NYT também se deve ao fato que o período compreendido em nossa análise assinala uma mudança nas relaçôes científicas brasileiras. Se, até a década de 1930, as influências francesas e posteriormente alemãs em nossas ciências médicas eram predominantes, a partir dos anos que antecedem a Segunda Grande Guerra, os Estados Unidos passaram a ser um país de destaque nas relaçôes científicas brasileiras. Com o decorrer da guerra, essas influências se ampliam ainda mais, fazendo com que, no período posterior ao conflito, muitos médicos brasileiros continuamente buscassem se especializar em cancerologia em universidade estadunidenses 5 .

No descritor de assunto do NYT, foi inserida a palavra "cancer". O serviço disponibilizado pelo jornal estadunidense apontou, inicialmente, cerca de duas mil ocorrências com o termo nos biênios 1931-1932 e 19481949. As páginas com os títulos e um pequeno resumo das notícias foram selecionadas, gravadas e arquivadas para análises.

Do total de notícias, foi eliminado o conteúdo que utilizava a palavra "cancer" em contextos que não eram sobre a doença. Assim, para a pesquisa realizada nos anos 1931-1932, foram selecionadas 240 notícias, em 25 páginas da Internet; nos anos 1948-1949, 300 notícias, em 31 páginas da Internet.

Em paralelo, averiguaram-se a quantidade e a variedade de artigos científicos publicados sobre o câncer no portal de periódicos científicos no US National Library of Medicine - National Institutes of Health (PuBMed) nas décadas de 1930 e 1940 . Essa busca se deveu em virtude do interesse em saber se, de alguma forma, a mídia daquela época reproduzia os resultados científicos publicados em periódicos de excelência, como nos dias atuais. No descritor de assunto para buscas, inseriu-se a palavra "cancer", delimitou-se o período escopo deste estudo (1931-1932 / 1948-1949) e permitiu-se pesquisa em qualquer idioma. 


\section{RESULTADOS E DISCUSSÃO}

\section{ABORDAGENS SOBRE CÂNCER ABAIXO DA LINHA DO EQUADOR}

Considerando os dois biênios estudados (1931-1932 e 1948-1949), foram encontradas, no primeiro ano foco de nosso estudo (1931), nove ocasiōes nas quais o câncer foi mencionado no jornal Correio da Manhã, incluindo até mesmo a publicidade de um medicamento para a pele. No ano seguinte, 1932, as ocorrências foram ainda menores e mais esparsas: apenas em seis ocasióes houve alguma menção à doença em qualquer reportagem. Os anos pesquisados da década de 1940 foram mais produtivos: em 1948, foram 30 ocorrências. Em 1949, a soma total voltou a cair, mas ficou ainda assim superior aos dois primeiros anos selecionados para este estudo: 11 ocorrências.

É importante ressaltar que em 1948 o SNC estabeleceu que o mês de novembro fosse dedicado a palestras e eventos com o objetivo principal de divulgar cientificamente os estudos da doença no país 5 . Provavelmente, em virtude desse fato, esse mês ganhou uma cobertura intensa do jornal Correio da Manhã. Em dezembro de 1948, o editor do jornal publicou um raro editorial em que discutiam os progressos em relação ao entendimento da doença e o que ainda precisava ser mais aprofundado.

Observando-se o total de ocorrências nesses quatro anos (56), obteve-se um quadro claro de baixa divulgação. Ao lançar um olhar mais detalhado nas matérias publicadas no Correio da Manhã sobre o câncer, o assunto era pautado principalmente quando acontecia uma nova descoberta ou algum cientista propunha novo método de combate tanto terapêutico como cirúrgico. Notícias sobre óbitos eram consideravelmente menos frequentes: em termos exatos, apenas uma matéria, entre as 56 , noticiava exclusivamente uma vítima da doença. Outras quatro reportagens apresentavam números gerais sobre a mortalidade da doença tanto no Brasil quanto nos Estados Unidos, e mais uma, em 1949, alertava para o aumento do número de vítimas fatais.

Desse modo, tem-se um total de 50 outras ocorrências relativas ao tratamento do câncer, de caráter mais científico ou por vezes didático e, em alguns casos específicos, com um tom publicitário. Este último grupo se refere às divulgaçóes de laboratórios que aproveitavam esse veículo da mídia para tornar público seus envolvimentos e tentativas de prevenção ou tratamento da doença, assim como aos anúncios de médicos especializados em cirurgias para retirada de tumor e pomadas contra o câncer de pele. Muitos desses anúncios, inclusive, eram feitos na seção de Classificados.

Devido à construção das seçôes do jornal, as notícias sobre o câncer não costumavam aparecer em páginas específicas. Havia editoriais destinados a temas de economia, esportes, vida cultural e os acontecimentos policiais e, em nenhum deles, havia espaço para notícias científicas. Apesar de, em 1948 e 1949, o Correio da Manhã possuir também um suplemento aos domingos com notícias voltadas à medicina e à ciência, poucas vezes o câncer teve destaque ali. No geral, as divulgaçóes das descobertas e teorias sobre o assunto vinham em notícias soltas entre uma seção e outra.

Importante também é o fato de que a maioria dessas notícias era proveniente de agências de notícias, ou seja, importada diretamente do exterior, mas não necessariamente as matérias eram escolhidas por representar um panorama do que se discutia sobre o tema nos jornais internacionais, mas sim pelo impacto presumido das matérias junto ao público nacional. Ao contrário da maioria das outras notícias na época, o jornal apenas reproduzia os destaques do mundo afora nesses casos, e muitas reportagens eram bem curtas, em função disso. Matérias sobre os avanços científicos realizados em laboratórios e centros de pesquisa nacionais recebiam sempre um tratamento diferenciado, com maior espaço para a cobertura, e por vezes possuíam entrevistas com cientistas e professores para embasamento dos fatos, como por exemplo, as realizadas durante a série de palestras sobre o câncer em novembro de 1948.

Curioso notar que o tom das notícias, em todo caso, costumava ser bastante positivo, como exemplificado na figura do Anexo. O foco na divulgaçáo de avanços acompanhado dos jargóes bélicos amplamente utilizados até os dias atuais, como "luta" ou "batalha" contra o câncer ${ }^{14}$ ou até mesmo referência como "praga", transmitiam a sensação de que esforços incansáveis estavam sendo feitos no sentido de encontrar uma cura para a doença ${ }^{14}$. Se essa repetiçáo de títulos, por um lado, parece náo apontar para uma fertilidade criativa dos jornalistas responsáveis, por outro parece indicar uma vontade expressa de tratar o assunto com otimismo e tranquilizar a população de que algo estaria sendo feito para superar o problema ${ }^{14}$.

\section{SOB 0 ENFOQUE AMERICANO}

No outro extremo do continente americano, foram publicadas no jornal NYT, no mesmo período, 540 matérias sobre câncer, um número quase dez vezes maior que as 56 ocorrências encontradas no Correio da Manhã do Brasil. Nos dois biênios estudados (1931-1932 e 1948-1949), o câncer já era um assunto relevante para os profissionais da mídia norte-americana, que escolhiam divulgar com mais regularidade os últimos acontecimentos sobre o tema.

As manchetes e o conteúdo das reportagens veiculadas sobre câncer no NYT impressionam pela diversidade de assuntos cobertos dentro da temática. Nos dois primeiros anos de análise, encontraram-se títulos como "Câncer é visto como um grupo de doenças” (26 de maio de 1931), 
mostrando a percepção moderna dos profissionais dessa mídia sobre a diversidade da doença. Já naquela época os pesquisadores tentavam alertar a populaçáo que a palavra câncer se relaciona a uma multiplicidade de doenças de diferentes formas de tratamento e prevenção, náo se referindo sempre ao mesmo tipo de mal, - como muitos imaginavam - e esses esforços continuam até hoje.

Foram observadas desde exposiçóes sobre o "pior flagelo" (20 de novembro de 1931) a técnicas como cirurgia, rádio e os raios $\mathrm{X}$ apontados "como os únicos agentes contra o câncer" (10 de outubro de 1931), até a síntese de uma substância química que, segundo a reportagem, era capaz de produzir tumores em animais (15 de janeiro de 1932). A gama variada de assuntos procurava despertar o interesse público norte-americano $\mathrm{e}$ alertar sobre a importância da prevenção e do diagnóstico precoce. Nesses primeiros anos da década de 1930, já era possível identificar "tratamento de guerra" às notícias sobre a doença ${ }^{14}$. Bons exemplos foram publicados nas ediçóes de fevereiro e de setembro de 1931. Em fevereiro, o lead (resumo que aparece no primeiro parágrafo da matéria) dizia "54 líderes internacionais do exército na guerra mundial contra o câncer saudaram o Dr. James Ewing, da Cornell University como o grande lutador contra o câncer e deram a ele um livro de homenagens", ou como na reportagem que afirma "a velha ideia do câncer ser um 'poderoso exército de soldados vitoriosos' muda a visão de células frágeis de parasitas."

Diante desse prisma, pôde-se observar que, tanto no Brasil como nos Estados Unidos, a abordagem sobre a doença com analogias bélicas se assemelhava bastante entre os dois países. Estudos mais recentes ${ }^{16-18}$ sobre o câncer apontam que mesmo na atualidade essas metáforas ainda persistem. Ao tratar a temática câncer com metáforas de guerra e imagens de "luta contra o inimigo", "batalha a ser vencida", a mídia daquela época como a atual legitima e reforça um retrato vivenciado pela própria sociedade em relação à doença como algo associado a muita dor e sofrimento.

Nesse biênio inicial, o que mais sobressaiu foram notícias sobre as conferências proferidas por eminentes cientistas, tratamento e a potencial cura da doença.

Em 1949, duas reportagens traziam alertas sobre diagnóstico precoce. No lead das notícias pôde se observar o destaque para a produção de um filme especialmente com uma campanha de diagnóstico precoce do câncer de mama, ensinando a mulher como se examinar ( 6 de dezembro) e outra que aponta um programa com cinco itens fundamentais para o diagnóstico precoce que, segundo a reportagem, "podem salvar milhôes de pessoas destinadas a morrer pela doença" (12 de setembro). Também é interessante apontar que já em 1949 (27 de fevereiro) uma notícia correlacionava o cigarro ao câncer de pulmáo, mostrando a possibilidade de o incremento do hábito tabagista nos últimos 25 anos ser um dos principais fatores para o aumento da incidência de câncer de pulmão entre os homens. Outro aspecto a ressaltar era o destaque dado pelo NYT à liberaçáo de recursos para a "luta contra o câncer". Em diversas ocasiôes, especialmente no segundo biênio de análise (1948-1949), o jornal americano trazia chamadas em seus títulos para recursos alocados nas pesquisas, em testes de diagnóstico e centros de tratamento.

Além dos recursos para o câncer, o NYT, nesse segundo biênio, permaneceu com a mesma linha editorial, dando destaque para as conferências e congressos sobre a temática, porém também uma ênfase grande foi dedicada às notícias sobre formas de diagnóstico e a importância da prevençấo e do diagnóstico precoce.

\section{SERÁ A POPULARIZAÇÃO DA CIÊNCIA UM REFLEXO DOS PERIÓDICOS CIENTÍFICOS?}

Após evidenciar as características dos conteúdos das matérias jornalísticas sobre o câncer nos jornais Correio da Manhã e The New York Times, nas décadas de 1930 e 1940, procurou-se identificar se essas notícias, de alguma forma, refletiam os resultados da pesquisa científica publicados em periódicos científicos no mesmo período, ou seja, os anos de 1931-1932 e 1948 e 1949. Foram realizadas buscas na base de dados do PubMed, em qualquer idioma; e foram encontrados, no biênio inicial (1931-1932), 99 artigos, dando um salto exponencial nos outros dois anos (1948-1949), alcançando 5.794 artigos em periódicos científicos, como exemplificado na Tabela 1.

Tabela 1. Correlação entre o número de matérias sobre câncer encontradas nos jornais Correio da Manhã e NYT, e de artigos científicos relacionados ao tema nos biênios de 1931-1932 e 1948-1949

\begin{tabular}{c|c|c|c}
\hline $\begin{array}{c}\text { Anos } \\
\text { analisados }\end{array}$ & $\begin{array}{c}\text { Correio } \\
\text { da } \\
\text { Manhá }\end{array}$ & $\begin{array}{c}\text { The New } \\
\text { York } \\
\text { Times }\end{array}$ & $\begin{array}{c}\text { Artigos } \\
\text { científicos }\end{array}$ \\
\hline 1931 e 1932 & 15 & 240 & 99 \\
\hline 1948 e 1949 & 41 & 300 & 5.794 \\
\hline
\end{tabular}

Nenhuma produção científica foi encontrada na língua portuguesa no banco de dados do PubMed nesses mesmos períodos. Isso não significa que os pesquisadores brasileiros não publicassem sobre câncer, mas que nenhuma revista brasileira ou portuguesa publicou sobre o tema no período. Esse dado é difícil de aferir, uma vez que muitos dos resultados mostrados no Pubmed não contêm informação sobre a nacionalidade da publicação, porém outra busca com o termo "Brazil" mostrou apenas três resultados para o biênio de 1931-32 (dois sobre febre amarela e um artigo de opiniáo sobre uma nova sociedade científica no Rio de Janeiro), e 40 para 1948-49, e nenhum era sobre câncer, sendo a maioria sobre doenças tropicais.

Os principais temas abordados pelos artigos publicados no biênio 1931-1932 foram as formas de tratamento do câncer (22 artigos), novas técnicas de cirurgia (10) e, 
especialmente a radioterapia, que começava a despontar (12). Apesar de ter sido um tema abordado pelas notícias de jornal, apenas três trabalhos tratavam da relação entre o câncer e o fumo. Dois deles abordavam especificamente o possível papel do fumo no desenvolvimento do câncer; outro, um editorial sobre câncer de pulmão da revista Cancer Medical Association, afirmava que a alta incidência nos índices de câncer de pulmão deveria estar relacionada ao tabagismo, que também obteve grande aumento na época. Os demais artigos desse biênio analisavam temas variados, como índices de mortalidade (5) em diferentes países, panoramas dos determinados tipos de cânceres, como de mama, reto, estômago, laringe e também sobre as pesquisas em câncer no geral. Alguns artigos também buscavam associaçóes do câncer com hereditariedade, outras doenças, e alteraçôes hormonais, entre outros fatores.

No biênio 1948-1949, foram identificadas 111 ocorrências correlacionadas ao tabaco, sendo que vários estudos eram sobre o vírus do mosaico, que é um vírus RNA que infecta plantas, especialmente o tabaco. Também foram identificados artigos associativos entre o fumo e problemas de gengivite, angina pectoris e o desgosto ao fumar como um dos sintomas de hepatite. $E$ ainda artigos que discutem como driblar a irritação do fumo com o uso de filtros eficientes; e mais: efeitos do tabaco em problemas gástricos e uma revisão da literatura sobre o efeito do tabaco na gravidez, crescimento fetal e lactação. Embora tenha sido possível identificar alguns artigos científicos relacionando o uso do tabaco à saúde nesses dois períodos, percebeu-se que um dos grandes destaques da época, no meio acadêmico, era relacionado à agricultura e às formas de preservação das plantações de tabaco, baseando-se em estudos sobre pragas.

Nessa época, aumentaram os trabalhos sobre novas terapias (1.049), sendo 299 sobre métodos cirúrgicos e 221 sobre radioterapia. Ao mesmo tempo, também cresceram os estudos nas mais diversas áreas da pesquisa em câncer.

\section{CONCLUSÃO}

Considerando todos os fatos expostos, pôde-se refletir sobre a divulgação do câncer no Correio da Manhá, comparando-a ao que foi publicado no NYT e aos periódicos científicos publicados no período. $\mathrm{O}$ que obteve-se é uma quantidade bastante baixa de retorno de informação aos leitores do periódico brasileiro das descobertas e avanços sobre a doença naquele período em relação aos norte-americanos. Se os elementos mais básicos da compreensão do câncer eram noticiados, como os índices de mortalidade e o conhecimento técnico que os cientistas possuíam no momento, muito em termos de informação ainda ficava em dívida. A quantidade de matérias publicadas era extremamente pequena quando comparada à divulgaçáo internacional, e se torna clara a ausência de reportagens mais personalizadas e aprofundadas.
Nas reportagens do NYT, o que surpreendeu foi observar a gama diversificada de assuntos tratados no mesmo período e a quantidade expressiva de espaço para informaçōes sobre a doença. Foi instigante perceber que a divulgação empreendida pelo jornal americano era de vanguarda, trazendo abordagens ainda hoje impressas e divulgadas na mídia como a biologia do câncer, fatores de risco associados à doença (tabagismo), hereditariedade, avanços científicos, experimentação animal, além de outras abordagens mais tradicionais como cura, tratamento, diagnóstico, prevenção, que condizem melhor com o panorama amplo das publicaçóes científicas dos períodos estudados.

Ao analisar o material encontrado na Biblioteca Nacional e lançando um olhar para os anos posteriores à década de 1940, percebeu-se que tanto a saúde pública quanto o jornalismo científico percorrem um longo e tortuoso caminho no Brasil, enfrentando dificuldades, às vezes intransponíveis; ou, na maioria das vezes, vibrando diante de conquistas diminutas.

A comparação entre a divulgação científica efetuada no Correio da Manhã e no NYT também se apresenta como um instrumento para a melhor compreensão do desenvolvimento do conhecimento público sobre a doença no país. Uma pesquisa, realizada pelo INCA, sobre a concepção da população brasileira a respeito do câncer, em sete capitais brasileiras, mostrou que um elevado percentual dos entrevistados ainda associa essa palavra à "morte", "dor" ou a ambas. Tal associação se apresenta como um significativo obstáculo aos programas de prevenção e diagnóstico precoce da doença. Em alguma medida, embora este artigo tenha limitaçóes por se basear em análises de apenas dois veículos de comunicação, as diferenças observadas no esforço comparativo que foram empreendidas podem ser fatores relacionados à falta de informação sobre a doença ainda hoje existente ${ }^{19}$.

Até bem pouco tempo, a temática câncer era um tabu na imprensa brasileira e talvez ainda o seja nos meios televisivos ${ }^{20}$, porém um trabalho contínuo de esclarecimento tanto dos profissionais da mídia como da sociedade é fundamental num país democrático, em que a informação é um direito de todos. Afinal, a informação jornalística tem como função servir de acompanhante e complemento ao progresso, e os dois fatores se potencializam ainda mais quando unidos.

\section{CONTRIBUIÇÕES}

Claudia Jurberg, Marina Verjovsky e Luiz Antonio Teixeira contribuíram na elaboração da metodologia e protocolo de análise, acompanhamento da pesquisa, redação e edição do manuscrito; Gabriel Pereira contribuiu com pesquisa na Biblioteca Nacional, análise do material coletado e redação inicial do manuscrito.

Declaraçáo de Conflito de Interesses: Nada a Declarar. 


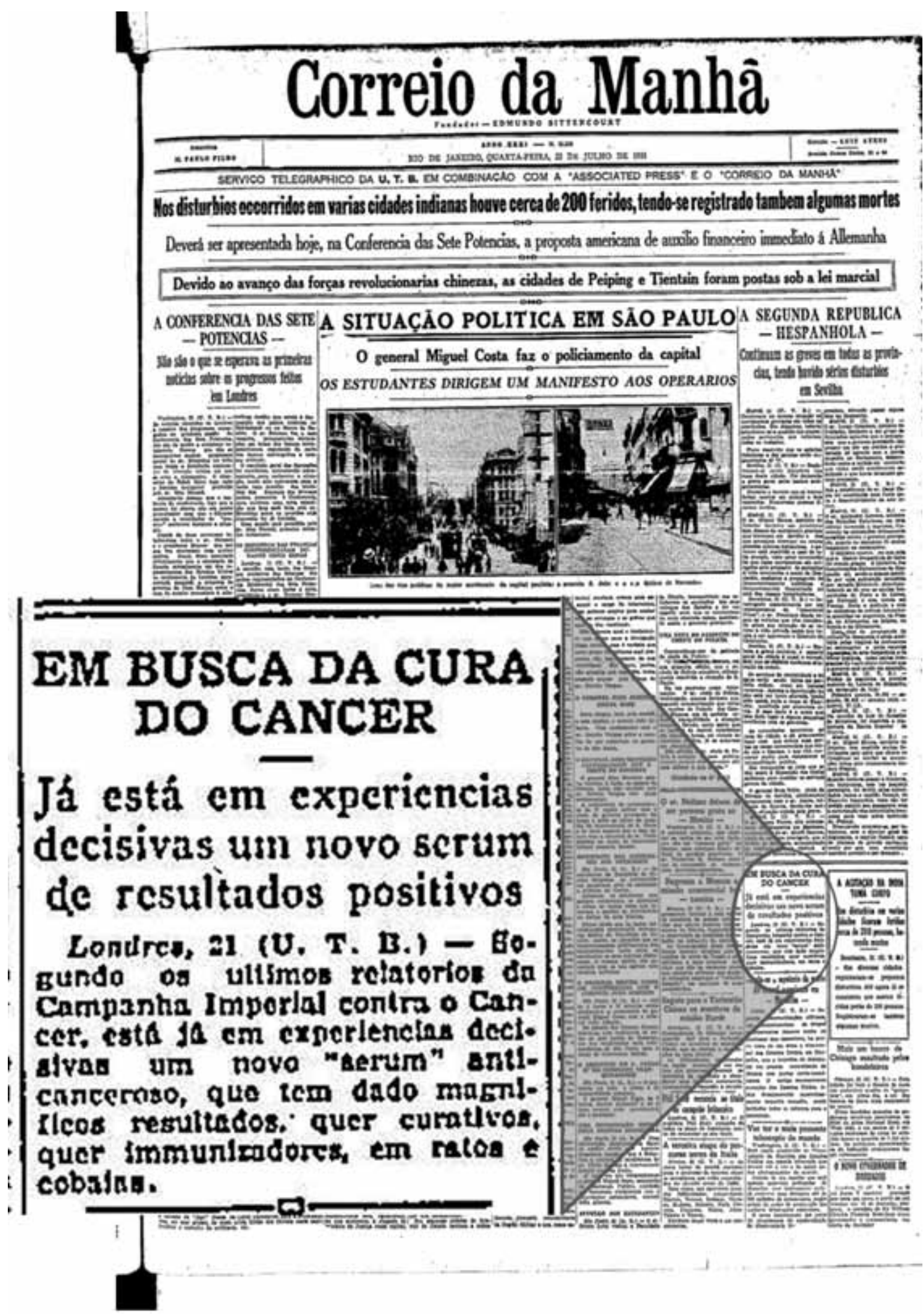

Figura 1. Notícia sobre câncer publicada no Correio da Manhã em 1931

Fonte: Acervo documental da Biblioteca Nacional (Brasil).

Obs.: A nota traz uma mensagem reproduzida de Londres onde se relatam experiências "decisivas" contra o câncer. 


\section{REFERÊNCIAS}

1. Escorel S, Teixeira LA. História das políticas de saúde no Brasil de 1822 a 1963: do Império ao desenvolvimentismo populista. In: Giovanella L, Escorel S, Lobato LVC, Noronha JC, Carvalho AI, organizadores. Políticas e sistema de saúde no Brasil. Rio de Janeiro: Editora FIOCRUZ; 2008. p. 115-55.

2. Lima NT, Fonseca CMO, Hochman G. A saúde na construção do Estado Nacional no Brasil: reforma sanitária em perspectiva histórica. In: Lima NT, Gerschman S, Edler FC, Manuel Suárez J, organizadores. Saúde e democracia: história e perspectivas do SUS. Rio de Janeiro: Editora FIOCRUZ; 2005. p. 27-58.

3. Hochman G. Reformas, instituições e políticas de saúde no Brasil (1930-1945). Educ rev. 2005;25:127-41.

4. Prata PR. Uneven development and the inequality of mortality in Brazil [Master's thesis]. Leeds: Leeds University, Department of Public Health Medicine; 1989.

5. Teixeira LA, Fonseca CO. De doença desconhecida a problema de saúde pública: o INCA e o controle do câncer no Brasil. Rio de Janeiro: Ministério da Saúde; 2007. 169 p.

6. Barbosa M. História cultural da imprensa: Brasil, 19002000. Rio de Janeiro: Mauad X; 2007. 262 p.

7. Bahia J. Jornal, história e técnica. 4a ed. Vol. 1, História da imprensa brasileira. São Paulo: Ática; 1990.

8. Sodré NW. História da imprensa no Brasil. [Rio de Janeiro]: Civilização Brasileira; [1966]. 583 p. (Coleção Retratos do Brasil; vol. 51).

9. Leal MJDR. Os jornais do Rio de Janeiro nas décadas de 40 e 50. XIV Colóquio Internacional de Comunicação para o Desenvolvimento Regional (REGIOCOM); 2009 jun 18-19; São Bernardo do Campo, BR.

10. Candiani HR. Journalist and intellectuals in the origins of the Brazilian press (1808-1822). Journalism. 2009;10(1):29-44.
11. Marques de Melo J. Journalistic thinking: Brazil's modern tradition. Journalism. 2009;10(1):9-27.

12. Ribeiro APG. Jornalismo, literatura e política: a modernização da imprensa carioca nos anos 1950. Estudos Históricos. 2003;(31):147-60.

13. Negreiros G. Jornalistas contam a História - 1: na década de 20, a agonia do regime: depoimento de Barreto Leite Filho [Internet]. Almanaque Folha de S. Paulo. 1979 jan 5 [citado $2012 \mathrm{mar}$ ]. Disponível em: http://almanaque. folha.uol.com.br/memoria_1.htm

14. Instituto Nacional de Câncer (Brasil). Resenha da luta contra o câncer no Brasil: documentário do Serviço Nacional de Câncer. 2a ed. Brasília: Ministério da Saúde; 2007. 435 p. (História da saúde no Brasil; 1).

15. Verjovsky M, Rêgo T, Jurberg C. O Jornal do Commercio: um breve exame das notícias de saúde. In: Massarani L, Jurberg C, Meis L, [organizadores]. Um gesto ameno para acordar o país: a ciência no Jornal do Commercio (1958-1962). Rio de Janeiro: Editora FIOCRUZ; 2011. p. 63-71.

16. Sontag S. Illness as metaphor. London: Penguin; 1991. $180 \mathrm{p}$.

17. Clarke J, Robinson J. Testicular cancer: Medicine and machismo in the media (1980-94). Health. 1999;3(3):263-82.

18. Grant JA, Hundley H. Images of the war on cancer in the Associated Press: Centering survivors and marginalizing victims. American Communication Journal. 2009;11(4):1-16.

19. Instituto Nacional de Câncer (Brasil). INCA divulga pesquisa de opinião dos brasileiros sobre o câncer [Internet]. Rio de Janeiro: INCA; 2007. [citado 2012 mar]. Disponível em: http://www.inca.gov.br/releases/ press_release_view.asp?ID $=1396$

20. Jurberg C, Verjovsky M. Nunca aos domingos: um estudo sobre a temática do câncer nas emissoras de TV brasileiras. Hist ciênc saúde-Manguinhos. 2010;17(supl 1):149-63. 


\begin{abstract}
Introduction: In the early decades of the last century, cancer was already characterized as one of the most lethal chronic degenerative diseases and began to demand more attention from Governments. Therefore, some countries undertook new policy measures, such as increasing investments in scientific research in search for a cure. Objective: This paper aims at characterizing the content of news stories on cancer in the Brazilian and North American newspapers Correio da Manhã and The New York Times, in the 1930s and 1940s, through analysis of the news published in four selected years (1931, 1932, 1948 and 1949). Method: We conducted research in the collection of documents at the Brazilian National Library and The New York Times digital archive. In parallel, we also performed analysis on cancer publications in the scientific journals at the same time. Results: While in the Correio da Manhä, we identified 56 news articles on that subject in the studied period; in the American Journal we identified 540 pieces of news, an amount nearly 10 times higher. Conclusion: The findings demonstrate a shy and sometimes naïve Brazilian press, faced with promises of miracle cures, such as ointments against skin cancer. Meanwhile, the U.S. media, 70 years ago, prioritized approaches on investments on disease research, highlighted lectures by subject matter experts and scientists, and even discussed the use of animal experimentation in cancer research; however, on some occasions, it has also bet on scientific innovations that history would show as fruitless initiatives.

Key words: Neoplasms/history; Newspapers/history; Journalism/history; Brazil; United States; Historical Article
\end{abstract}

\title{
Resumen
}

Introducción: A principios del siglo pasado, el cáncer ya se caracterizaba como una de las más letales enfermedades crónico-degenerativas y empezó a exigir más atención de los gobiernos. Por lo tanto, algunos países adoptaron nuevas medidas políticas, tales como el incremento en la investigación científica para encontrar una cura. Objetivo: Este artículo intenta resaltar características del contenido de los noticiarios sobre el cáncer en los periódicos brasileño y norteamericano Correio da Manhã y The New York Times, en los años 1930 y 1940, mediante el análisis de noticias publicadas en cuatro ańos seleccionados (1931, 1932, 1948 y 1949). Método: Han sido realizados estudios en el acervo documental de la Biblioteca Nacional y del acervo digital del New York Times. En paralelo, también se llevó a cabo un análisis sobre el tema cáncer en revistas científicas disponibles en el portal PubMed y publicadas durante la misma época. Resultados: Mientras que en el Correio da Manhã han sido identificados 56 reportajes sobre el tema en el periodo estudiado, en el periódico norteamericano habían 540 noticias, cantidad casi 10 veces mayor. Conclusión: Los resultados demuestran una prensa brasileńa tímida y a veces ingenua, ante promesas de curas milagrosas, tales como pomadas contra el cáncer de piel. Mientras tanto, las noticias norteamericanas priorizaban temas como inversión en la investigación de la enfermedad, conferencias de expertos en la utilización de la experimentación con animales en la investigación del cáncer, aunque en ocasiones también apostaron por en innovaciones científicas que la historia después reveló infructuosas.

Palabras clave: Neoplasias/historia; Periódicos/historia; Periodismo/historia; Brasil; Estados Unidos; Artículo Histórico 